\title{
An audit of state sector intensive care services in Sri Lanka
}

\section{AB Yatawatte ${ }^{1}$, CR Wanniarachchi ${ }^{1}$ and CDA Goonasekera ${ }^{2}$}

(Index words: Distribution, equipment, specialities, staffing)

\begin{abstract}
Objective To survey the facilities, functioning characteristics, bed strength, manpower, operational practices and the distribution of the Intensive Care Units (ICU) of Government Hospitals in Sri Lanka.
\end{abstract}

Design A cross-sectional observational study.

Method Interview of the sister or the nurse in charge of each unit by telephone using a structured questionnaire.

Setting Department of Anaesthesiology, Faculty of Medicine, University of Peradeniya.

Study population All intensive care units of the government hospitals in Sri Lanka.

Measurements Bed strength, facilities, functioning characteristics, manpower and equipment.

Results Fifty two intensive care units were identified in the island. Two units could not be contacted over the telephone and one refused to participate. Of the 49 ICUs studied $28(57.1 \%)$ were located in teaching hospitals, six $(12.2 \%)$ in provincial hospitals, $13(26.5 \%)$ in base hospitals and two $(4.1 \%)$ in special hospitals. Twenty five $(51 \%)$ of the 49 ICUs were multidisciplinary, three $(6.1 \%)$ general medical, four (8.2\%) general surgical and the remainder were of medical, surgical and paediatric subspecialities. The minimum acceptable standard of a ventilator: bed ratio of $1: 1$ was seen in $28(57 \%)$ and a nurse : bed ratio of $1: 1$ was seen in $37(75.5 \%)$ ICUs. A 24-hour resident medical officer was available in 46 (93.9\%) of the 49 ICUs. ICUs are mostly located in larger cities. The lowest ICU coverage (one ICU for about 1.2 million people) was seen in the Uva Province.

Conclusions ICUs in Sri Lanka are mainly located in teaching hospitals. The standards and management strategies vary widely.

\section{Introduction}

Intensive care has emerged as a distinct speciality in the world over the last 40 years [1]. The importance of mechanical ventilation was realised during polio epidemic in Copenhagen in 1952 where the mortality rates reduced from $90 \%$ to $40 \%$ following its introduction [2]. This led to the recognition of the importance of close monitoring and vital function support in the treatment of life-threatening diseases.

${ }^{1}$ Lecturer, ${ }^{2}$ Senior Lecturer, Department of Anaesthesiology, Faculty of Medicine, University of Peradeniya, Sri Lanka. Correspondence: CDAG, e-mail: <cgoonase@slt.lk >(Competing interests: none declared). Received 1 December 2003 and revised version accepted 10 Febuary 2004. 


\section{Papers}

Information on intensive care services in Sri Lanka is scarce. Several studies have looked into disease patterns and regional patterns [3], but this has not been extended to the whole island. Studies in other countries have looked into services provided and improvements in outcome [4]. The adequacy of medical and nursing staff $[2,5]$, therapeutic interventions, and clinical outcome in patients $[6,7]$ have been studied extensively in these countries.

Intensive care is not only a medically important service, but also a politically sensitive issue, because of the costs involved for its maintenance and the public demand for it. Although it is recommended that $15 \%$ of total bed strength of hospitals should be equipped for critical care, most countries have provision for only $1 \%$ to $2 \%$ of their total bed strength for critical care. In Sri Lanka, the bed availability is substantially low, perhaps below $1 \%$, and there is no governing body or a planning institute that scrutinises the standards of such units. The quality of care is directly related to manpower and equipment. A critical analysis of intensive care services in our country is needed before considering management changes to improve patient outcome.

\section{Methods}

We surveyed all labelled intensive care units (ICUs) in this country, and their facilities and functioning characteristics. A structured data form was used to obtain relevant information from the sister or nurse in charge of each unit by a telephone interview. All ICUs in government hospitals were traced by tracking patient transfers. Each ICU contacted was asked from which hospitals they received patients, and to which hospitals they transferred patients for intensive care when their beds were full. As the demand far exceeded the availability for critical care beds, this exercise was useful to locate all ICUs in the state sector hospitals. Each Province was covered including the north and east. Non-functional or closed units were excluded. Data collection was completed within a 2-week period in November 2002 and analysed using SPSS computer software.

The facilities available were calculated based on accepted minimum standards for intensive care in general [8]. For example, a nurse: bed ratio of 1:1 was calculated as such if there were 4 nurses allocated for each bed in an ICU as this was the requirement for one nurse to be able to cover one bed 24 hours a day, 7 days a week. The distribution of ICUs in the nine provinces of the island was determined and their service burden was expressed as a ratio against population. The population statistics were obtained from the 2001 Sri Lanka population census.

\section{Results}

A total of 52 units were identified in the island. Two units could not be contacted over the telephone during the study period and one unit refused to provide information. Of the 49 ICUs studied, 28 (57.1\%) were located in teaching hospitals, six $(12.2 \%)$ in provincial hospitals, $13(26.5 \%)$ in base hospitals and two $(4.1 \%)$ in special hospitals. The mean bed strength of an ICU was 5.78 (SD 3.5).

Of the 49 ICUs 25 (51\%) were multidisciplinary, three $(6.1 \%)$ were general medical, four $(8.2 \%)$ general surgical, and the remaining units were that of medical, surgical and paediatric subspecialties (Table 1). Anesthesiologists were the consultants in charge in 27 (55.1\%), physicians and paediatricians were incharge of six units (12.2\%) each. Combined specialty administration was seen in another six (12.2\%) units. In the remaining 4 units the specialty in charge was unclear.

Table 1. The type of intensive care unit

\begin{tabular}{lcc}
\hline & Frequency & $\%$ \\
\hline Multidisciplinary & 25 & 51 \\
Medical & 3 & 6.1 \\
General surgical & 4 & 8.2 \\
Paediatric & 4 & 8.2 \\
Neonatal & 3 & 6.1 \\
Neurosurgical & 2 & 4.1 \\
Cardiothoracic & 4 & 8.2 \\
Neurological & 1 & 2 \\
Accident and emergency & 1 & 2 \\
Coronary care & 2 & 4.1 \\
Total & $\mathbf{4 9}$ & $\mathbf{1 0 0}$ \\
\hline
\end{tabular}

A predominant team management of patients was seen in $40(81.6 \%)$ ICUs. A ventilator:bed ratio of $1: 1$ or more was seen in $26(53 \%)$ units, and a nurse:bed ratio of $1: 1$ or more was seen in $37(75.5 \%)$. In the remaining units there were not a sufficient number of ventilators to cover for each bed, and one nurse supervised more than one bed at a time. A 24-hour resident medical officer was available in 46 (93.9\%) ICUs. A blood gas analyser was available in 35 units $(71 \%)$ and a defibrillator in 45 $(92 \%)$. A pulse oximeter for each bed was available in 18 units, i.e. pulse oximeter: bed ratio of $1: 1$ or above in $37 \%$ ICUs. A bedside ECG monitor was available for each bed in $30(61 \%)$ ICUs.

The location of ICUs was examined by province and population (Table 2). Most ICUs were located in the main cities of the country, i.e. Colombo, Kandy and Galle. However, lowest population burden per ICU was noted in the Western and North Central Provinces whereas the highest population burden per ICU was noted in the Uva and Sabaragamuwa Provinces (Table 2). 
Table 2. The distribution of ICUs in Sri Lanka by province and the population burden in each province for each ICU

\begin{tabular}{lccc}
\hline Province & Population & $\begin{array}{c}\text { No. of } \\
\text { ICUs }\end{array}$ & $\begin{array}{c}\text { Population/ } \\
\text { ICU Ratio }\end{array}$ \\
\hline Western & 5361185 & 26 & 206199 \\
North Central & 1105663 & 4 & 276415 \\
Central & 2414973 & 7 & 344996 \\
North Western & 2157711 & 5 & 431542 \\
Southern & 2277145 & 5 & 455429 \\
Northern & 1040963 & 2 & 520481 \\
Eastern & 1415949 & 2 & 707974 \\
Sabaragamuwa & 1787938 & 2 & 893969 \\
Uva & 1170728 & 1 & 1170728 \\
\hline
\end{tabular}

$\mathrm{ICU}=$ Intensive Care Unit

\section{Discussion}

Our findings show the status of critical care facilities in Sri Lanka and, more importantly, the aspects needing improvement. We found that the distribution of ICUs are in parallel with other health care facilities in the country and concentrated mostly around Colombo, Galle and Kandy, necessitating a long and difficult transfer for patients requiring critical care services from the peripheries. Most ICUs were located in teaching hospitals, with several specialised ICUs in each hospital. These units often had an input from multiple specialties and easy access for advanced investigations such as CT scanning. The two most important factors in critical care that made a significant reduction of morbidity and mortality, i.e. 24-hour resident medical officer and a nurse:bed ratio of $1: 1$, was unfortunately not seen in all our ICUs. The minimum monitoring standards today require an oximeter and ECG monitor at the bedside of each patient even in a high dependency unit [9]. Unfortunately, only one-third of our ICUs had these facilities. This implies that in the remaining ICUs monitoring equipment was shared, inevitably leading to interruptions in continuous monitoring and increasing the risk of cross-infection.

The average bed strength of our ICUs falls within the recommended range of 4 to 8 [9]. The bed occupancy however, was not assessed in this study and it is recommended to be about $70 \%$, with the capability of accommodating $95 \%$ of emergency requests. Most of the ICUs in Sri Lanka are multidisciplinary (51\%), managing medical, surgical, obstetrics and gynaecological and paediatric patients. Units dedicated to one major discipline were less common and managed by a team comprising a primary care consultant physician, surgeon and anesthesiologists. One-third of our ICUs were highly specialised for neurosurgical, neurological, coronary, cardiothoracic and neonatal care. Although current evidence supports 'closed' versus 'open' ICUs for better care for patients $[10,11]$, 'open' policies were operational in the majority of our ICUs. An open ICU has unlimited access to mul- tiple doctors who are free to admit and manage their patients. A closed ICU has admission, discharge and referral policies under the control of intensivists. Improved cost benefits are likely with a closed ICU, and patient care is likely to be better than open ICUs, especially if the intensivists have full clinical responsibilities [8].

Ventilator:bed ratio was 1:1 in the majority of stations and only $10 \%$ of units had one ventilator for more than two beds. These were mainly coronary care and paediatric (including neonatal) units. Pulse oximeter: bed ratio of $1: 1$ was seen only in $40 \%$ of units. In others the number available was less than the number of beds.

There was one ICU for 20000 population in the Western Province, whereas in Uva Province one ICU had to cater for 1.2 million. Thus, there is an obvious misdistribution of ICU services in the country.

\section{Conclusions}

ICUs in Sri Lanka are mainly located in teaching hospitals. There is a clear variability in the standards and operational practices islandwide and also a misdistribution of services. Some of the ICUs do not meet even the standards of a high dependency unit.

\section{Acknowledgements}

We thank Drs R Pallemulla and D Bandara for their advice, and all sisters and incharge nurses of ICUs for providing information. Mrs Chamalie Herath and Mrs Anoma Seneviratna gave us clerical help.

\section{References}

1. Dudley HAF. Intensive care: a specialty or a branch of anaesthetics? British Medical Journal 1987; 294: 459-60.

2. Bennett D, Bion J. ABC of intensive care. British Medical Journal 1999; 318: 1468-70.

3. Vasanthathilaka VWJK, Goonasekera CDA. An audit of admissions to an intensive care unit in a regional centre in Sri Lanka. Ceylon Medical Journal 1997; 42: 145-8.

4. Celis E. ICUs worldwide: results of a nationwide survey of Colombian intensive care units. Critical Care 2002; 6: 405-6.

5. Hogan J. Staff ratios in intensive care: are they adequate? British Journal of Nursing 2000; 9: 817-9

6. Morrow BC, Lavery GG, Blackwood BM, Ball IM, McLeod HN, et al. The provision of adult intensive care in Northern Ireland with reference to the role of high dependency care. Ulster Medical Journal 1996; 65: 39-46.

7. Zimmerman JE, Rousseau DM, Duffy J, et al. Intensive care at two teaching hospitals: an organizational case study. American Journal of Critical Care 1994; 3: 129-38. 


\section{Papers}

8. Oh TE. Design and organization of intensive care units. In: Bersten AD, Soni N, Oh TE, eds. Oh's Intensive Care Manual. 5th edn. Edinburgh: Butterworth Heinemann, 2003: 3-10.

9. Minimum standards for intensive care units. Policy document IC-1, 1997, Faculty of Intensive Care: Australian and New Zealand College of Anaesthetists, Melbourne.
10. Knaus WA, Draper EA, Wagner DP, Zimmerman JE. An evaluation of outcome from intensive care in major medical centres. Annals of Internal Medicine 1986; 104: 410-8.

11. Brown JJ, Sullivan G. Effect on ICU mortality of a fulltime critical care specialist. Chest 1989; 96: 127-9. 